\title{
SIMULTANEOUS TRAPPED ELECTRON AND
}

\author{
MAGNETIC TAIL FIELD \\ OBSERVATIONS
}

\author{
BY \\ DONALD J. WILLIAMS \\ NORMAN F. NESS
}

GPO PRICE

CFSTI PRICE(S) \$

Hard copy (HC)

3.00

JUNE 1966

Microfiche (MF)

ff 653 July 65

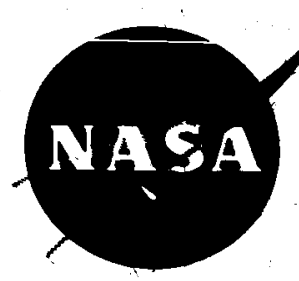

GODDARD SPACE FLIGHT CENTER GREENBELT, MARYLAND

1
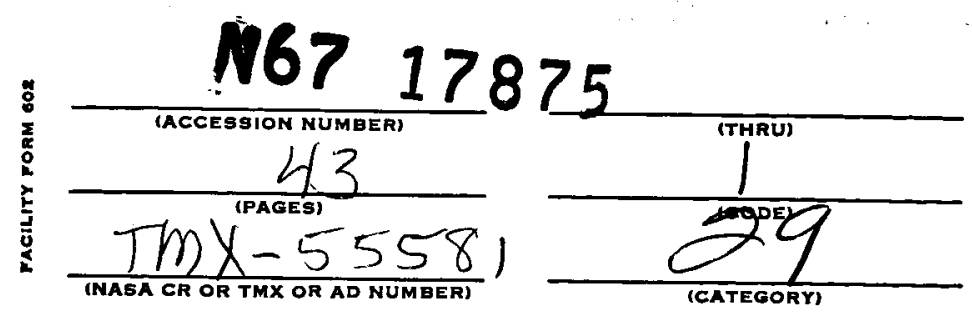


\section{Donald J. Williams and \\ Norman F. Ness}

June 1966 


\begin{abstract}
Using data from the polar orbiting satellite $196338 \mathrm{C}$, the behavior of the high latitude energetic ( $\geq 280 \mathrm{kev}$ ) electron trapping boundary, $\Lambda_{c}$, at $1100 \mathrm{~km}$ is presented for the period March 15 through June 3,1964 . A sudden collapse of $\Lambda_{c}$ to lower latitudes during the onset of magnetic storms, as indicated by $K_{p}$ and $D_{s t}$, is found to be a characteristic feature of the low altitude trapped electron population. Details of this behavior are presented and discussed. In addition, during this time period, the NASA IMP-1 satellite sampled field characteristics in the geomagnetic tail. Correlated observations of the simultaneously observed behavior during magnetic disturbances of the $1100 \mathrm{~km}$ trapped electron population and of the field strength in the tail are presented. In three cases there is agreement and in one case disagreement with the latitude decreases which are predicted with an extended geomagnetic tail configuration. These results are considered to be direct evidence of the important influence exerted by the geomagnetic tail field in governing not only the quiet time trapped particle distribution, but also the behavior of the trapped particle population during magnetic storms.
\end{abstract}

$N 67-17875$

$$
\text { Anthor }
$$

SWELDING PrGE ELANK NOT MLNiL. 


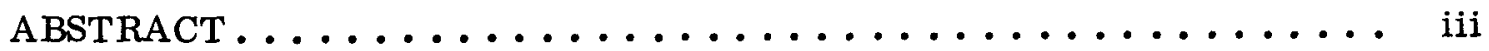

INTRODUCTION $\ldots \ldots \ldots \ldots \ldots \ldots \ldots \ldots \ldots \ldots \ldots \ldots \ldots \ldots$

SATELLITES AND DETECTORS ................. 1

TRAPPED ELECTRON RESULTS $\ldots \ldots \ldots \ldots \ldots \ldots \ldots \ldots \ldots \ldots$

CORRELATED RADIATION BELT AND MAGNETIC TAIL

OBSERVATIONS .................... 4

SUMMARY AND DISCUSSION $\ldots \ldots \ldots \ldots \ldots \ldots \ldots \ldots$

ACKNOWLEDGMENTS ..................... 11

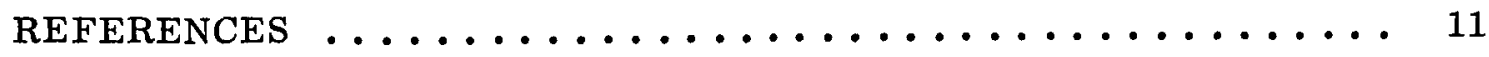

PRECEDING PAGE PIANK NOT FILMED. 


\title{
SIMULTANEOUS TRAPPED ELECTRON \\ AND MAGNETIC TAIL FIELD OBSERVATIONS
}

\author{
by \\ Donald J. Williams \\ Norman F. Ness
}

\section{INTRODUCTION}

A recent letter (Ness and Williams, 1966) has described correlations observed between simultaneous observations of outer zone trapped electrons at $1100 \mathrm{~km}$ and of the magnetic field strength $\sim 30 R_{E}$ (earth radii) in the earth's magnetic tail. The reported observations concerned a magnetic disturbance which occurred on April 1, 1964. It was found that at the height of this disturbance, the low altitude, high latitude electron trapping boundary on the midnight meridian had undergone a marked collapse of $\sim 5^{\circ}$ toward lower latitudes. Simultaneous to this behavior of the trapped electron population, it was observed that the field strength some $30 R_{E}$ in the earth's magnetic tail increased. This was interpreted as evidence of additional, formerly closed lines of force being significantly extended into the tail region, thereby increasing the tail field magnitude and lowering the low altitude, high latitude trapping boundary. Quantitatively favorable comparisons were obtained with the expectations of a magnetic field model having an extended tail configuration.

Data for the above correlation were obtained from the APL satellite 1963 38C and the NASA IMP 1, or Explorer 18 satellite. Additional trapped electron and magnetic field correlations have been obtained for the period March 15 June 3, 1964 when IMP 1 was imbedded within the earth's magnetic tail. The objective of this paper is to present and discuss these additional simultaneous trapped electron and magnetic field observations.

The temporal history of the trapped electron trapping boundary on the nightside hemisphere and its correlation with $K_{p}$ and $D_{s t}$ values for the period under study will also be presented. A similar temnoral history of the tail field as observed by IMP 1 during this period has been presented by Behannon and Ness (1966).

\section{SATELLITES AND DETECTORS}

1963 38C: During the March 15 - June 3, 1964 period under study, satellite 1963 38C sampled electron intensities on the nightside hemisphere from the local times of 0400 hours to 2000 hours. A description of the instruments and of 
initial outer zone observations has been presented in Williams and Smith (1965), Williams and Palmer (1965), Williams and Mead (1965) and Williams (1966).

Briefly, satellite 1963 38C was launched on September 28, 1963 into a nearly circular polar orbit having a $1140 \mathrm{~km}$ apogee, a $1067 \mathrm{~km}$ perigee, an $89.9^{\circ}$ inclination and a $107.5 \mathrm{~min}$. period. The satellite was magnetically aligned to the extent of possessing $a \leq 6^{\circ}$ residual oscillation about the local line of force except for the first three days after launch.

The detector of interest is an integral electron spectrometer consisting of five $1000 \mu$ thick surface barrier detectors. The channel to be discussed is one sensitive to electrons of energy $E_{e} \geq 280 \mathrm{kev}$. The spectrometer is oriented to look out normal to the satellite alignment axis and thus after alignment monitors the intensity of trapped electrons mirroring at or very near the point of observation.

IMP 1: The IMP 1 satellite was launched on November 27, 1963 into a highly elliptical orbit with an initial apogee of $31 \mathrm{R}_{E}$ and an orbital period of 93.5 hours. During the March 15 - June 3, 1964 period under study, the angle between the line of apsides of the IMP 1 orbit and the earth-sun line ranged from $122^{\circ}$ west to $198^{\circ}$ west of the sun. A description of the instrumentation and of initial magnetospheric results has been presented in Ness et al (1964), Ness (1965), Ness et al (1965), and Behannon and Ness (1966). The instrumentation provided vector field measurements in the tail for field strengths of less than 40 gamma with an accuracy of \pm 0.25 gamma. The average field strength beyond $\sim 10 R_{E}$ during this three month interval was approximately 16 gamma.

\section{TRAPPED ELECTRON RESULTS}

Data from 206 nightside passes of satellite 1963 38C have been obtained during the period March 15 - June 3, 1964. The electron spectrometer data pertaining to trapped electrons of energy $E_{e} \geq 280 \mathrm{kev}$ have been displayed as intensity (true count rate) versus invariant latitude $\left(\Lambda \equiv \cos ^{-1} / \sqrt{\mathrm{L}}\right)$ profiles for all recorded passes.

A characteristic feature of the behavior of the $\geq 280 \mathrm{kev}$ trapped electron population in such latitude profiles is a striking collapse of the high latitude trapping boundary to lower latitudes during magnetic storms. This effect has been illustrated for the magnetic storms of March 29 and April 1, 1964 by Ness and Williams (1966) and Williams (1966). It is further illustrated here in Figure 1 for the magnetic disturbance of May 10, 1964. In Figure 1 are shown the six available nightside passes (within local times of $2140 \mathrm{hrs}$. $-2210 \mathrm{hrs}$.) for the 
period May 9-11, 1964. A sudden commencement magnetic disturbance occurred at 0035 hours May 10, 1964. The numbered arrows in the plot of $\mathrm{K}_{\mathrm{p}}$ values show the time sequence of the corresponding numbered passes.

Passes 1 and 2 of Figure 1, obtained prior to the disturbance, display similar and typical quiet time latitude profiles. Pass 3 , obtained $\sim 4$ hours after the sudden commencement but prior to the sustained increase in $\mathrm{K}_{\mathrm{p}}$, shows a profile similar to passes 1 and 2, having a cutoff at $\sim 65^{\circ}$. Pass 4 , obtained at the height of the disturbance, displays the characteristic collapse of the high latitude cutoff to lower latitudes, in this case to $\sim 58^{\circ}$. Pass 5 , taken $\sim 3-1 / 2$ hours after pass 3 , and pass 6 , taken after the disturbance has subsided, show a gradual recovery with the high latitude cutoff approaching the pre-storm values. The interpretation and correlation of this effect with magnetic tail field measurements will be discussed in later sections.

The high latitude cutoff $\left(\Lambda_{c}\right)$ has been defined at a detector count rate of 1 count per second. As a check on the consistency of such a low count rate cutoff, a high latitude boundary has also been defined and recorded at a detector count rate of 10 counts per second. Figure 2 shows the behavior of the trapped, $\geq 280$ kev electron nightside high latitude cutoffs, $\Lambda_{c}$, for the entire 81 day period under study. The solid circles and open circles represent the high latitude boundary defined at $1 \mathrm{cps}$ and $10 \mathrm{cps}$ respectively. $D_{\mathrm{ST}}$ values (Behannon and Ness, 1966) and the 3 hour $\mathrm{K}_{\mathrm{p}}$ averages are also shown along with all sudden commencements reported by ten or more stations (Lincoln, $1965 \mathrm{a}$ and b). The disturbances during which the trapped electron data were correlated with IMP 1 data are indicated by vertical lines.

The typical nature of the high latitude cutoff lowering during magnetic disturbances is evident in Figure 2. An apparent exception to this consistent behavior is the seemingly confused response from March 15 - March 23, 1964. Note that the $\mathrm{D}_{\mathrm{ST}}$ behavior at this time is also not very marked nor characteristic. The scatter in $\Lambda_{c}$ values does appear to be indicative of magnetic activity. The effect of the sudden commencement of March 21 was missed due to inappropriate phasing of the satellite orbit, data acquisition and hence data sampling.

For the remainder of the time period however, the behavior of $\Lambda_{c}$ is seen to be remarkably consistent in its response to magnetic activity as measured by $D_{s t}$. For example, the response of $\Lambda_{c}$ is seen to correlate very well with the temporal variations of $D_{s t}$ and $K_{p}$ throughout the two storms of May 10 and May 13, 1964.

From Figure 2 it is possible to obtain the dependence of the $\Lambda_{c}$ collapse on $\mathrm{D}_{\mathrm{s} t}$ magnitude. For the $\sim 60 \mathrm{y}$ range observed, this dependence is in agreement with the auroral arc southern latitude dependence on $D_{s t}$ as reported by Akasofu (1965). 
A characteristic time appropriate for the changes in the trapped electron population indicated in Figure 2 is estimated to be $\leq 3$ hours, i.e. within the resolution of the $K_{p}$ averages. This estimate stems from a study of the less significant fluctuations displayed in Figure 2. Also the data sampling rate during major events where a sudden large decrease of $\Lambda_{c}$ is observed is such that the best estimate obtainable for the response time is $\leq 6-9$ hours.

This is illustrated in Figures 3,4 , and 5 where the $\Lambda_{c}$ and $K_{p}$ values are shown on an expanded time scale for the periods April 15-22, April 24- May 2, and May 7- May 19, 1964. The trend of the $\Lambda_{c}$ values on April 15, and 16 and particularly April 18 in Figure 3, on April 24-27 in Figure 4, and on May 9 in Figure 5 indicates that the trapped electron low altitude $\Lambda_{c}$ response is in phase with variations in the $\mathrm{K}_{\mathrm{p}}$ averages, i.e. occurs within a 3 hour time period.

An additional interesting characteristic dislpayed in Figures 3-5 is the recovery of $\Lambda_{c}$ toward prestorm values even while the $\mathrm{K}_{\mathrm{p}}$ values remain high throughout the magnetic disturbance. Thus the correlation between $\Lambda_{c}$ and magnetic activity (low $\Lambda_{c}$ correlates with high, or increasing $K_{p}$ ) decreases after about the initial 24 hours of an extended disturbance. This can be seen in the April 18-21 disturbance in Figure 3 and the May 13-18 disturbance of Figure 5. In Figure $4, \Lambda_{c}$ is seen to correlate well with the behavior of $K_{p}$ from April 24 to April 27. However, as $\mathrm{K}_{\mathrm{p}}$ rapidly rises to its highest level at $\sim 1800$ hours April 27, the $\Lambda_{c}$ values show a tendency to recover to quiet time values and essentially reach these undisturbed values on April 28 while the $K_{p}$ values remain high. This effect will be correlated with simultaneous magnetic tail field measurements in the next section.

If the return of the high latitude trapping boundary to pre-storm values is considered to be indicative of the re-establishment of a "quiet time" magnetospheric configuration, then the continued high $\mathrm{K}_{\mathrm{p}}$ values at these times may be more a measure of ionospheric currents rather than of gross magnetospheric perturbations.

\section{CORRELATED RADIATION BELT AND MAGNETIC TAIL OBSERVATIONS}

During the 81 day period under study, March 15 - June 3, 1964, there were six magnetic storm events for which

1) Outer zone data were available from $196338 \mathrm{C}$ and

2) Magnetic field data in the earth's magnetic tail were available from IMP-1.

These six events, indicated by vertical lines in Figure 2, occurred at 1525 hours April 1, 0020 hours April 17, 14XX hours April 27, 0035 hours May 10, 
1301 hours May 13, and 2229 hours May 23, 1964. Details of the tail field behavior and its correlations with ground observations have been presented for all but the April 17 event by Behannon and Ness (1966).

Quantitative correlations of the trapped electron data and the magnetic tail field data have been obtained for the above cases in the following manner. Three hour averages of the tail field magnitude, $\overline{\mathrm{F}}$, and direction, $\theta$ and $\phi$, were obtained so that a direct comparison could be made with the $\mathrm{K}_{\mathrm{p}}$ averages. The angles $\theta$ and $\phi$ are solar ecliptic latitude ( + is north) and longitude $\left(180^{\circ}\right.$ is the anti-solar direction) respectively.

From these tail field values, an approximate midnight meridian high latitude trapping boundary was obtained by considering field line closure in an extended magnetic tail field configuration. The model used was that constructed by Williams and Mead (1965) to fit the low altitude energetic trapped electron population spatial distribution during magnetically quiet periods, under the assumption of adiabatic invariant conservation. The predictions of this model, using observed tail field strengths, were then compared directly with simultaneously observed high latitude boundary values, $\Lambda_{c}$.

The current sheet spatial parameters (Williams and Mead, 1965) were held fixed for all six events at an inner edge of $8 R_{E}$ and an outer edge of $200 R_{E}$. Field strengths as observed by IMP-1 were used to determine an expected value of $\Lambda_{c}$. Figure 6 shows the predicted $\Lambda_{c}$ values as a function of tail field magnitude for the quoted current sheet parameters.

The six events will now be discussed individually. April 1, 1964: Figure 7 displays $\mathrm{K}_{\mathrm{p}}, \Lambda_{\mathrm{c}} \overline{\mathrm{F}}, \theta$, and $\phi$ for the event of April 1, a moderately severe storm having a sudden commencement reported by 4 stations at 1525 hours. It is this event for which the initial trapped electron-magnetic tail correlations were reported (Ness and Williams, 1966).

A strong positive correlation exists between the tail field magnetide, $\bar{F}$, and the $\mathrm{K}_{\mathrm{p}}$ averages. This correlation is somewhat weakened near midday, April 2. At this time IMP- 1 approached to within $1 R_{E}$ from the neutral sheet and entered a depressed field region probably affected by charged particle field line loading (Behannon and Ness, 1966; Anderson and Ness, 1966).

The solid line in the $\Lambda_{c}$ scale represents the predicted high latitude trapping boundary of the field model discussed above using the tail field values shown. Experimentally observed cutoffs are also shown with solid and open circles again corresponding to boundaries defined at $1 \mathrm{cps}$ and $10 \mathrm{cps}$ respectively. 
Figure 7 shows that while the absolute position of the predicted and observed trapping boundaries differ by an average of $\sim 4^{\circ}$, the magnitude of the boundary collapse, $\sim 6^{\circ}$, can be explained by the behavior of the tail field for this event. The low values of $\Lambda_{c}$ (theoretical) on April 2, reflect the low values of $\bar{F}$ as discussed in the correlation with $\mathrm{K}_{\mathbf{p}}$.

It is interesting to note that while the trapped electron boundary returned to prestorm values on April 2, electron islands were observed in the tail (Anderson and Ness, 1966).

April 17, 1964: The sudden commencement event occurring at 0020 hours April 17 is shown in Figure 8. This is the only event in which the observed boundary collapse could not be predicted from the observed tail field behavior. As is seen in Figure 8 , the observed boundary shift is $\sim 6^{\circ}$ whereas the predicted shift, based on the behavior of $\overline{\mathrm{F}}$, is at most $\sim 2-1 / 2^{\circ}$.

A neutral sheet crossing is seen to occur at $\sim 0300$ hours April 18. The temporal response of $\bar{F}$ is limited due to the proximity of IMP-1 to the neutral sheet. This may explain the above discrepancy between observed and predicted trapped electron boundary shifts.

April 27, 1964: Figure 9 shows a moderate event commencing at 14XX hours, April 27. The detailed $\Lambda_{c}$ behavior displayed in Figure 4 was discussed in the previous section. The observed trapped electron boundary positions are seen to accurately track the trend of the $K_{p}$ averages through 1500 hours, April 27. At the time the $K_{p}$ values suddenly increase to their maximum value and remain at an enhanced level until $\sim 1200$ hours April 28. After the $K_{p}$ increase at 1500 hours April 27, the observed trapped electron boundaries show a recovery to predisturbance values, although the $K_{p}$ values remain high as shown in Figure 9.

As IMP emerges from perigee, the tail field is seen to be at the rather high value of 30-35 gammas. After a slight increase occurring at 1500 hours April 27, in coincidence with the $\mathrm{K}_{\mathrm{p}}$ increase, the tail magnitude, $\mathrm{F}$, decreases to more normal values even though $\mathrm{K}_{\mathrm{p}}$ remains high.

Thus after initially correlating with the $\mathrm{K}_{\mathrm{p}}$ values, both $\Lambda_{c}$ (experimental and theoretical) and $\bar{F}$ tend toward typically quiet time values during a time in which $K_{p}$ remains high. Figure 9 shows that the behavior of the trapped electron high latitude boundary agrees well with the observed behavior of the tail field.

This recovery of $\bar{F}$ and $\Lambda_{c}$ during relatively high $\mathrm{K}_{\mathrm{p}}$ values is consistent with $K_{p}$ being, at this time, more a measure of ionospheric currents rather than gross magnetospheric distortions. If this is the case, then it is also possible that the 
rapid field fluctuations observed in both the ground magnetograms and in the tail field during the first 12 hours of April 28, (Behannon and Ness, 1966) may have been generated close to the ionosphere.

May 13, 1964: Figure 10 presents the data from a sudden commencement event occurring at 1301 hours May 13. It is seen that the behavior of $\Lambda_{c}$ is in good agreement with the behavior of $\bar{F}$ through May 13. Departures are noted at 03000600 hours, May 14. However, at this time IMP approaches to within $3 R_{E}$ of the neutral sheet and finally crosses the neutral sheet at $\sim 0000$ hours May 15 . That the response of the tail field is limited due to its proximity to the neutral sheet on May 14, is supported by the lack of any clear correlation between the tail field and the $K_{p}$ increase on that day.

May 10 and May 23, 1966: Figures 11 and 12 show the final two events in which it was possible to attempt a correlation between the behavior of the trapped electron population and the tail field magnitude. These two events are inconclusive in relating to the present study and demonstrate an "out of phase" character which can exist between two sets of independently sampled data.

In Figure 11, trapped electron data during the May 10 event is available only at the time that IMP is in the neutral sheet (IMP approached to within $1 R_{E}$ of the neutral sheet at $\sim 1800$ hours, May 10 , with a crossing occurring at $\sim 0300$ hours May 11).

The sudden commencement at 2229 hours, May 23 occurred while IMP- 1 was at perigee. A characteristic $\Lambda_{c}$ response is shown in Figure 2. However, trapped electron data are not available during additional magnetic activity occurring slightly over a day after the sudden commencement (Figure 12).

Summary of Correlations: Six events, Figure $7-12$, have been discussed which allowed the possibility of obtaining simultaneous trapped electron and magnetic tail field measurements.

In three of the events, April 1, April 27-28, and May 13 (Figures 7, 9 and 10) the high latitude boundary of the outer zone trapped electron population behaves in a manner consistent with the simultaneously observed behavior of the magnetic field in the geomagnetic tail. Moreover, the magnitude of the trapped electron boundary motion is in fair quantitative agreement with the results of an extended tail model (Williams and Mead, 1965) using the observed tail field strengths.

In one event, April 17 (Figure 8), the trapped electron high latitude boundary collapses more than is expected from the field model used, given the observed variation in the tail field magnitude. The possibility of a limited tail field response 
due to proximity to the neutral sheet is offered as an explanation for the anomalous behavior.

In two events, May 10 and May 23 (Figures 11 and 12), the particle and field data are out of phase and no quantitative results can be obtained.

\section{SUMMARY AND DISCUSSION}

The following points summarize the present observations.

1. The low altitude, energetic ( $\geq 280 \mathrm{kev})$ trapped electron population characteristically displays a sudden collapse of the high latitude boundary, $\Lambda_{c}$, during magnetic disturbances.

2. The magnitude of the trapped electron high latitude boundary collapse, when taken as a function of $D_{s t}$ value, is in agreement with the auroral arc results of Akasofu (1965) over the $\sim 60 \gamma$ range of $D_{s t}$ values observed.

3. The response time of $\Lambda_{c}$ following the onset of magnetic activity is within the resolution of the data i.e., $\leq 3$ hours.

4. There is a tendency for $\Lambda_{c}$ to return to pre-storm values during an extended magnetic disturbance, even though $\mathrm{K}_{\mathrm{p}}$ values remain at an enhanced level.

5. Quantitative correlations of the trapped electron high latitude boundary collapses with simultaneous observations of the field strength in the earth's magnetic tail show three cases which agree and one which disagrees with the predictions of an extended tail magnetic field model.

The motion of low altitude trapping boundaries to lower latitudes during magnetic disturbances has been noted previously for $\geq 40 \mathrm{kev}$ electrons (Maehlum and O'Brien, 1963) and for $\geq 280 \mathrm{kev}$ electrons (Williams and Palmer, 1965). The fact that $\geq 40 \mathrm{kev}$ and $\geq 280 \mathrm{kev}$ trapped electrons have the same nightside high latitude trapping boundary, (Williams and Mead, 1965) implies that the $\geq 40 \mathrm{kev}$ electrons will also characteristically exhibit trapping boundary collapses during magnetic storms. Thus it is expected that most of the present results can be extended to at least the $40 \mathrm{kev}$ trapped electron population.

In the present investigation, extending from March 15 through June 3, 1964, we have been able to correlate this trapped electron behavior with simultaneous observations of the field strength in the earth's magnetic tail. These correlations have been compared with the predictions of an extended tail configuration. 
The field model used was one originally constructed to fit the quiet time spatial distribution of trapped $\geq 280 \mathrm{kev}$ electrons, assuming conservation of the adiabatic invariants. This model (Williams and Mead, 1965), employing a current sheet and consequent tail configuration similar to that observed (Ness, 1965) and suggested (Piddington, 1960; Axford et al, 1965; Dessler and Juday, 1965), was quite successful in explaining quiet time electron distributions as observed at $1100 \mathrm{~km}$ and thus demonstrated the strong influence of the geomagnetic tail in determining quiet time trapped particle spatial distributions. In this present study current sheet parameters were held fixed at an inner edge of $8 \mathbf{R}_{E}$ and an outer edge of $200 R_{E}$ for all available cases. Using observed tail field strengths, high latitude trapping boundary variations were predicted by identifying this boundary, $\Lambda_{c}$, with the last closed field line in the extended tail configuration.

With such a model, the $\Lambda_{c}$ collapses may be considered to be due to additional formerly closed lines of force being extended well out into the tail region, possibly forming some of the electron islands found there (Anderson et al, 1965; Anderson, 1965).

In each of the three cases observed where the magnitude of the $\Lambda_{c}$ motion agreed with the field model predictions using observed tail field strengths, a difference in the absolute position of the observed and predicted boundaries was noted. This difference amounted to a few degrees and varied from one event to another. This discrepancy has been noted and discussed previously (Williams and Mead, 1965). Contributing factors are the need to use a more appropriate current sheet, the need for readjustment of the coefficients defining the field due to the boundary currents, the neglect of ring current effects, and the fact that a trapping boundary defined at a lower count rate would result in a higher cutoff latitude.

Of these factors, the effect of defining a trapping boundary at a lower count rate appears least important and should not raise trapping boundaries by more than $\sim 0.5^{\circ}$. Ring current magnitudes and resultant effects remain unknown but could be significant. A readjustment of the boundary current field coefficients is required in a self consistent calculation of the magnetospheric configuration.

Probably most important is the need to use a more realistic current sheet. Such a current sheet should exhibit a radial dependence as implied by tail field observations (Speiser and Ness, 1966). Furthermore, recent measurements (Bame et al, 1966) indicate a sheet thickness of $\sim 6 R_{E}$ at $17 R_{E}$ and an extension of the sheet across the magnetospheric tail. Thus a current system in the tail region having spatial characteristics similar to that discussed by Axford et al, 1965) is indicated. 
Nevertheless, in three cases, the $\Lambda_{c}$ motion is in good agreement with the predictions of the presently used simplified tail configuration employing simultaneously observed tail field strengths. We consider this as direct evidence of the important role played by the geomagnetic tail in governing the behavior of the trapped particle population during magnetic storms.

Note that the effect of the tail field increase need not be a sudden, violent opening of formerly closed field lines to explain the observed $\Lambda_{c}$ motion. An alternative to the actual opening of field lines is a gentle, but still significant, extension of field lines while conserving the first two adiabatic invariants,

$$
\mu=\frac{\mathrm{p}^{2}}{2 \mathrm{mB}}
$$

and

$$
\mathbf{J}=\mathbf{p I}
$$

Here $\mathrm{p}=$ momentum, $\mathrm{B}_{\mathrm{M}}=$ mirror point $\mathrm{B}$ value, and $\mathrm{I}=$ integral invariant

$$
I=\int_{M}^{M *}\left(1-\frac{B}{B_{M}}\right)^{1 / 2} d s .
$$

Since for low altitude mirroring particles, I is essentially a measure of the length of the field line between mirror points, a field line extension under conservation of $\mathrm{J}$ will yield particle deceleration. Particle deceleration, in turn will raise the altitude of the mirror point under $\mu$ conservation. Both of these effects will produce an intensity decrease at low altitudes for threshold detectors under normal outer zone spectral conditions. The relative importance of this effect and that of field line opening and the latitude dependence of these effects requires detailed calculations of invariant surfaces and their readjustments under a changing tail configuration. Such calculations will require the more realistic current sheet discussed above.

The $\leq 3$ hour response time of $\Lambda_{c}$ following the onset of magnetic activity may now be considered as an upper limit on the time required by the magnetosphere and the trapped particle population to readjust to variations in the tail field configuration.

In addition, the recovery of $\Lambda_{c}$ to pre-storm values during extended magnetic disturbances even while $\mathrm{K}_{\mathrm{p}}$ remains at an enhanced level, implies that a. "quiescent" magnetospheric configuration exists during periods of increased ground magnetic activity. This is consistent with $K_{p}$ being, at times, more an indication of ionospheric currents than gross magnetospheric distortions. 


\section{ACKNOWLEDGMENTS}

It is a pleasure to acknowledge the efforts of Mr. R. W. McEntire in the initial phases of this analysis.

This work was supported in part by the Bureau of Naval Weapons, Department of the Navy, under contract NO w 62-0604-C, and in part by a National Aeronautics and Space Administration grant.

\section{REFERENCES}

Akasofu, S.-I, The auroral oval, the auroral substorm and their relations with the internal structure of the magnetosphere, Univ. of Iowa Report \#65-37, November 1965.

Anderson, K. A., Energetic electron fluxes in the tail of the geomagnetic field, J. Geophys. Res., 70, 4741-4763, 1965.

Anderson, K. A., H. K. Harris, and R. J. Paoli, Energetic electron fluxes in and beyond the earth's outer magnetosphere, J. Geophys. Res., 70, 1039-1050, 1965.

Anderson, K. A., and N. F. Ness, Correlations of magnetic fields and energetic electrons on the IMP-1 satellite, Goddard Space Flight Center Report X-612-66-109, March 1966.

Axford, W. I., H. E. Petschek, and G. L. Siscoe, Tail of the magnetosphere, J. Geophys. Res., 70, 1231-1236, 1965.

Bame, S. J., J. R. Asbridge, H. E. Felthauser, R. A. Olson, and I. B. Strong, Electrons in the plasma sheet of the earth's magnetic tail, Phys. Rev. Let., $16,138-142,1966$.

Behannon, K. W., and N. F. Ness, Magnetic storms in the earth's magnetic tail, J. Geophys. Res., 71, 2327-2351, 1966.

Dessler, A. J., and R. D. Juday, Configuration of auroral radiation in space, Planetary Space Sci., 13, 63-72, 1965.

Lincoln, J. V., Geomagnetic and solar data, J. Geophys. Res., 70, 1227-1229, 1965a. 
Lincoln, J. V., Geomagnetic and solar data, J. Geophys. Res., 70, 2233-2239, $1965 \mathrm{~b}$.

Maehlum, B., and B. J. O'Brien, Study of energetic electrons and their relationship to auroral absorption of radio waves, J. Geophys. Res., 68, 997-1010, 1963.

Ness, N. F., C. S. Scearce, and J. B. Seek, Initial results of the IMP-1 magnetic field experiment, J. Geophys. Res., 69, 3531-3569, 1964.

Ness, N. F., The earth's magnetic tail, J. Geophys. Res., 70, 2989-3005, 1965.

Ness, N. F., C. S. Scearce, J. B. Seek, and J. M. Wilcox, A summary of results from the IMP-1 magnetic field experiment, Space Res., 6 , to be published 1966.

Ness, N. F., and D. J. Williams, Correlated magnetic tail and radiation belt observations, J. Geophys. Res., 71, 322-325, 1966.

Piddington, J. H., Geomagnetic storm theory, J. Geophys. Res., 65, 93-106, 1960.

Speiser, T. W., and N. F. Ness, The neutral sheet in the geomagnetic tail; its motion, equivalent currents, and field line connection through it, to be published.

Williams, D. J., and A.M. Smith, Daytime trapped electron intensities at high latitudes at 1100 kilometers, J. Geophys. Res., 70, 541-556, 1965.

Williams, D. J., and W. F. Palmer, Distortions in the radiation cavity as measured by an 1100 kilometer polar orbiting satellite, J. Geophys. Res., 70, 557-567, 1965.

Williams, D. J., and G. D. Mead, A nightside magnetospheric configuration as obtained from trapped electrons at 1100 kilometers, J. Geophys. Res., 70, 3017-3029, 1965.

Williams, D. J., Outer zone electrons, Proceedings of the Advanced Study Institute, "Radiation Trapped in the Earth's Magnetic Field" 151-168, to be published 1966. 

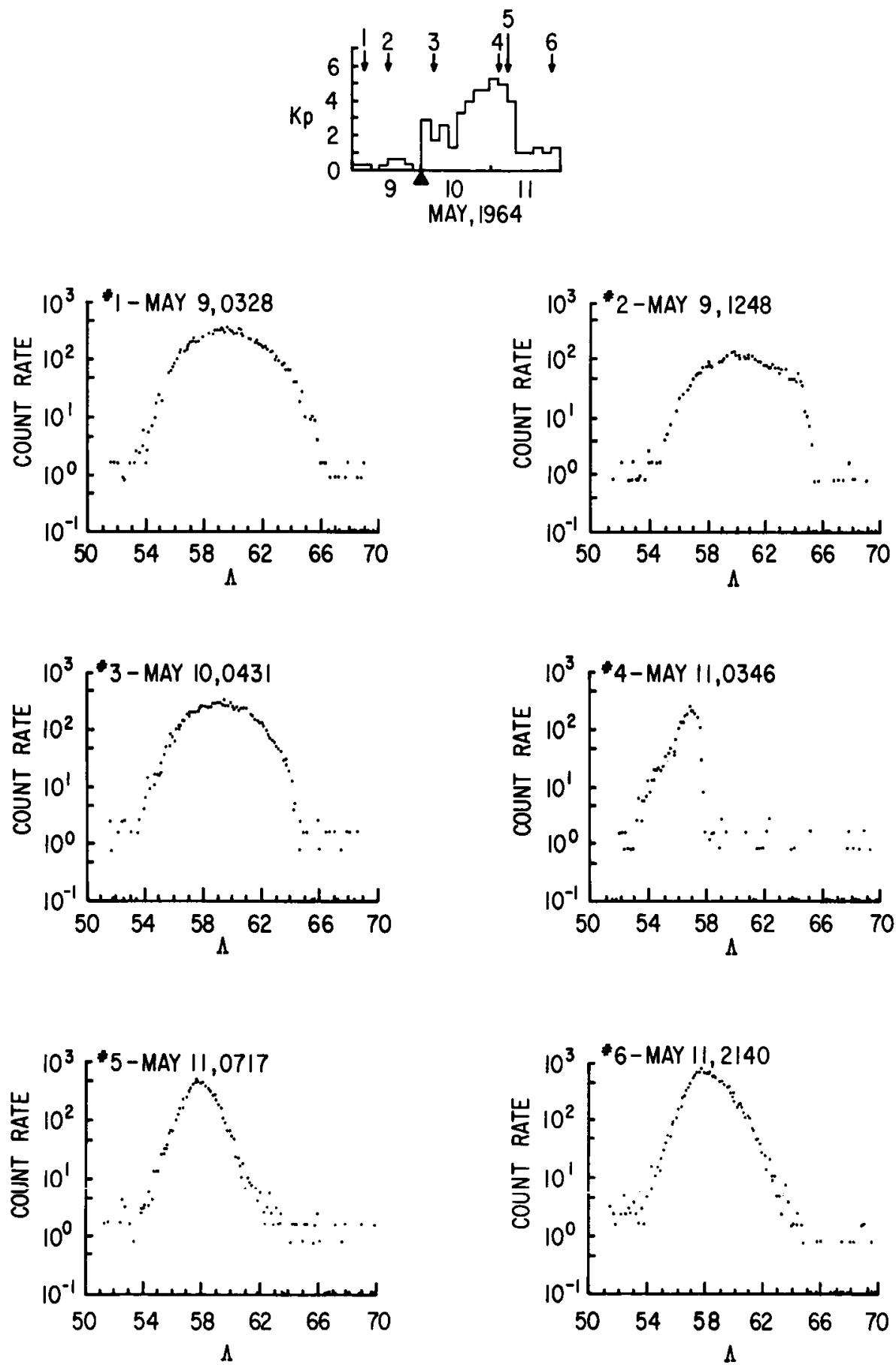

Figure 1-Intensity of trapped $\geq 280$ kev electrons af $1100 \mathrm{kms}$ versus invariant latitude, $\Lambda=\operatorname{arc} \cos L^{-1 / 2}$. Six passes are shown obtained before, during, and ofter the magnetic disturbance of May 10, 1964. The numbered arrows in the $K$ inset correspond to the pass numbers shown. Pass number 4 displays the characteristic collapse, during magnetic disturbance of the high latitude trapping boundary. Multiplication of count rates by 500 gives directional flux values (electrons $/ \mathrm{cm}^{2} \mathrm{sec}$ ster) 


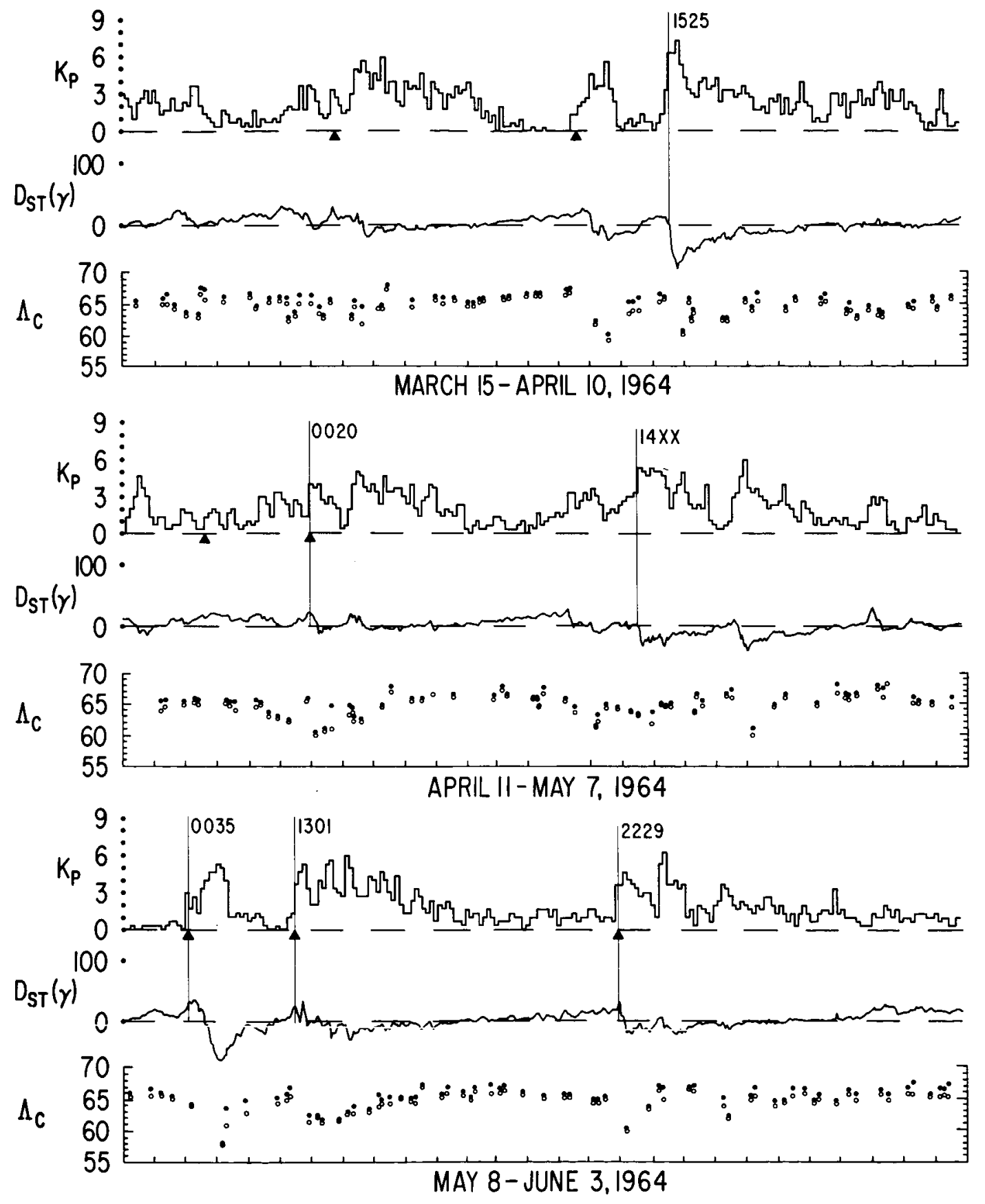

Figure 2-Plot of the $\geq 280 \mathrm{kev}$ electron high latitude trapping boundary $\Lambda_{c}$, and the $K_{p}$ and $D_{s, t}$ values for the period under study. Solid and open circles in the $\Lambda_{c}$ plot represent high latitude boundaries defined at $1 \mathrm{cps}$ and $10 \mathrm{cps}$ respectively. The vertical lines point out the six events yielding correlations of the $\Lambda_{c}$ behavior with simultaneous magnetic field observations in the geomagnetic tail. 


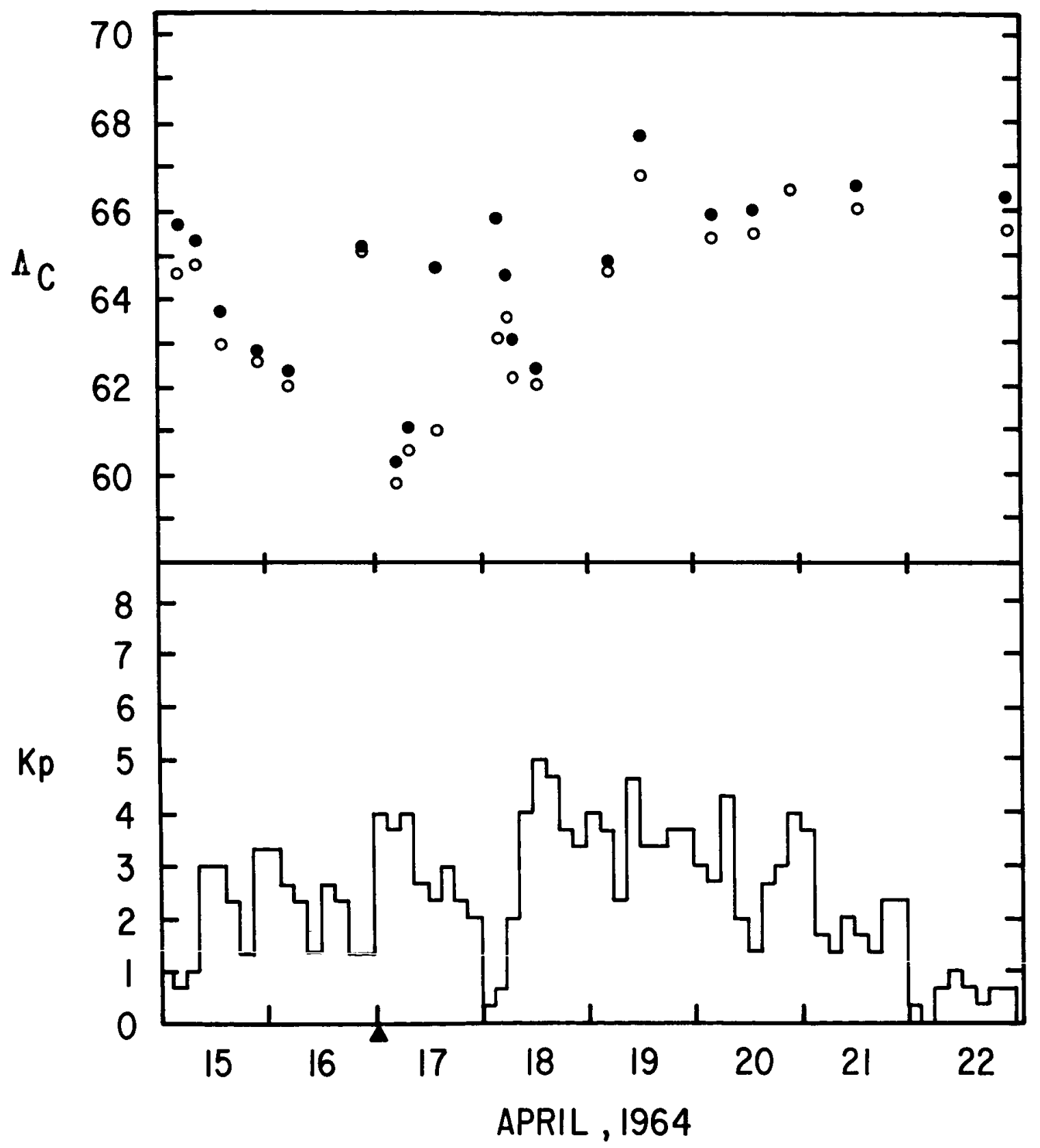

Figure 3-Expanded plot of $\Lambda_{c}$ and $K_{p}$ for the period April 15-22, 1964. Again, the solid and open circles represent high latitude trapping boundaries defined at $1 \mathrm{cps}$ and $10 \mathrm{cps}$ respectively. See text for discussion. 


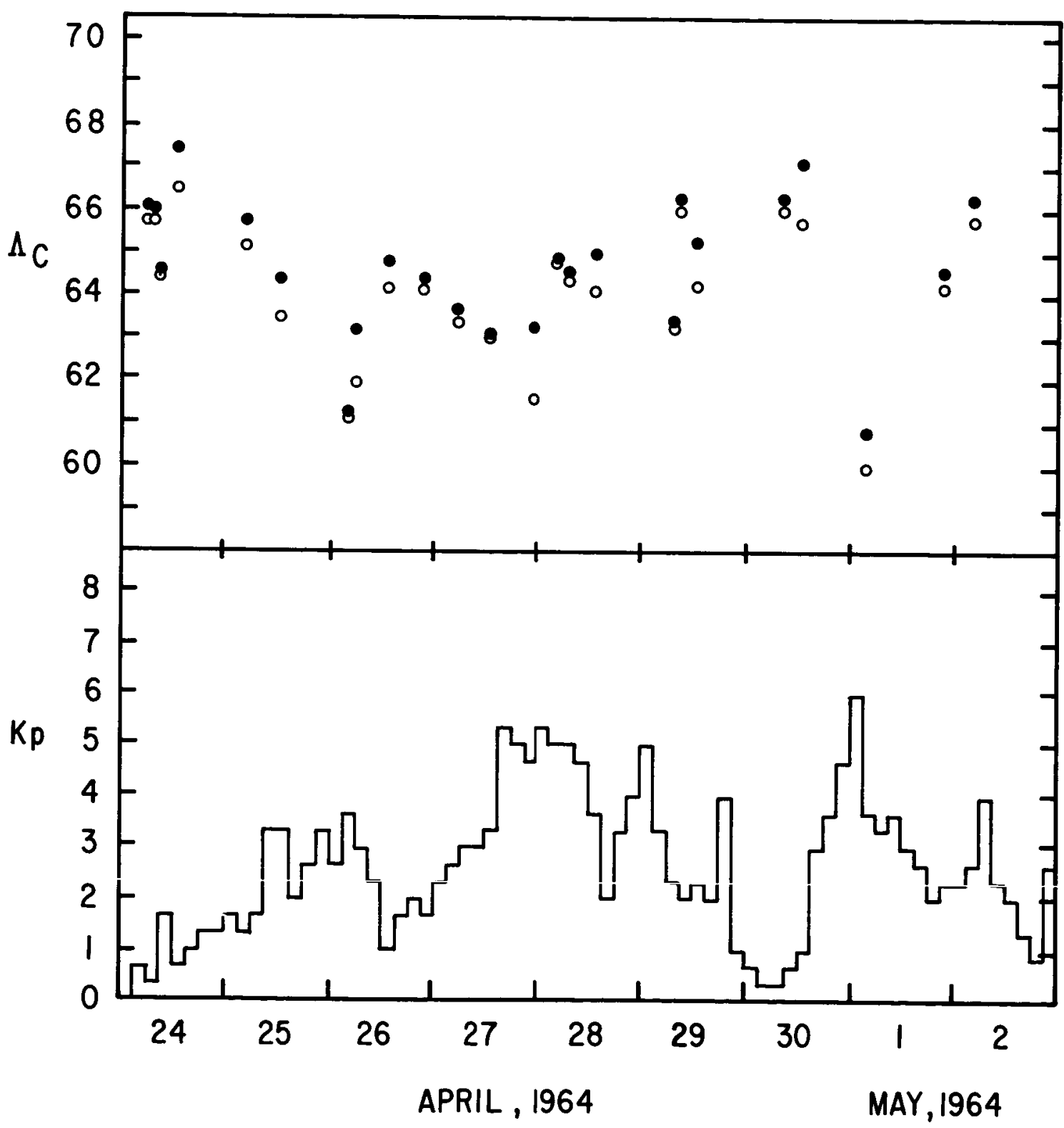

Figure 4-Same as Figure 3 but for the period April 24 - May 2, 1964. 


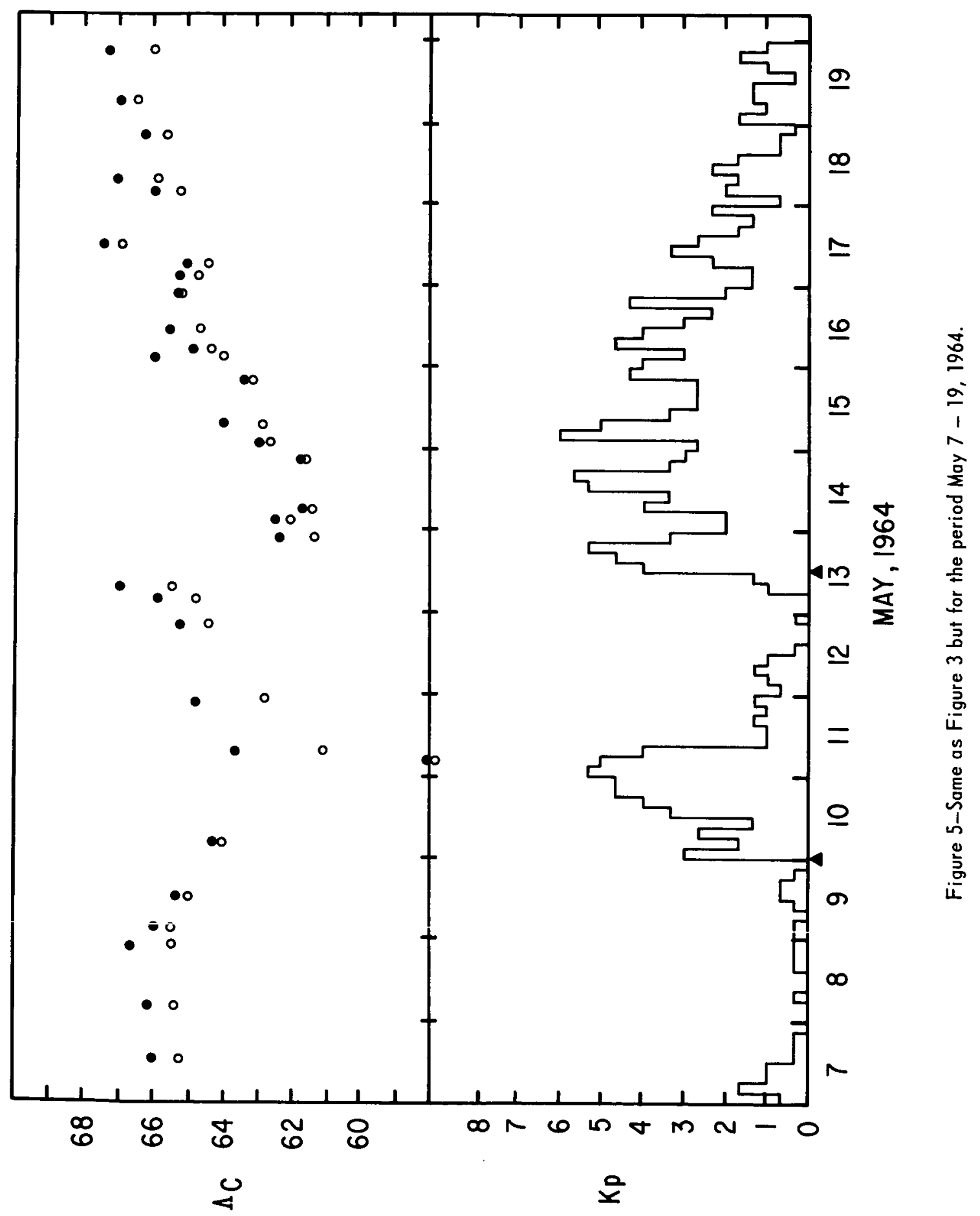




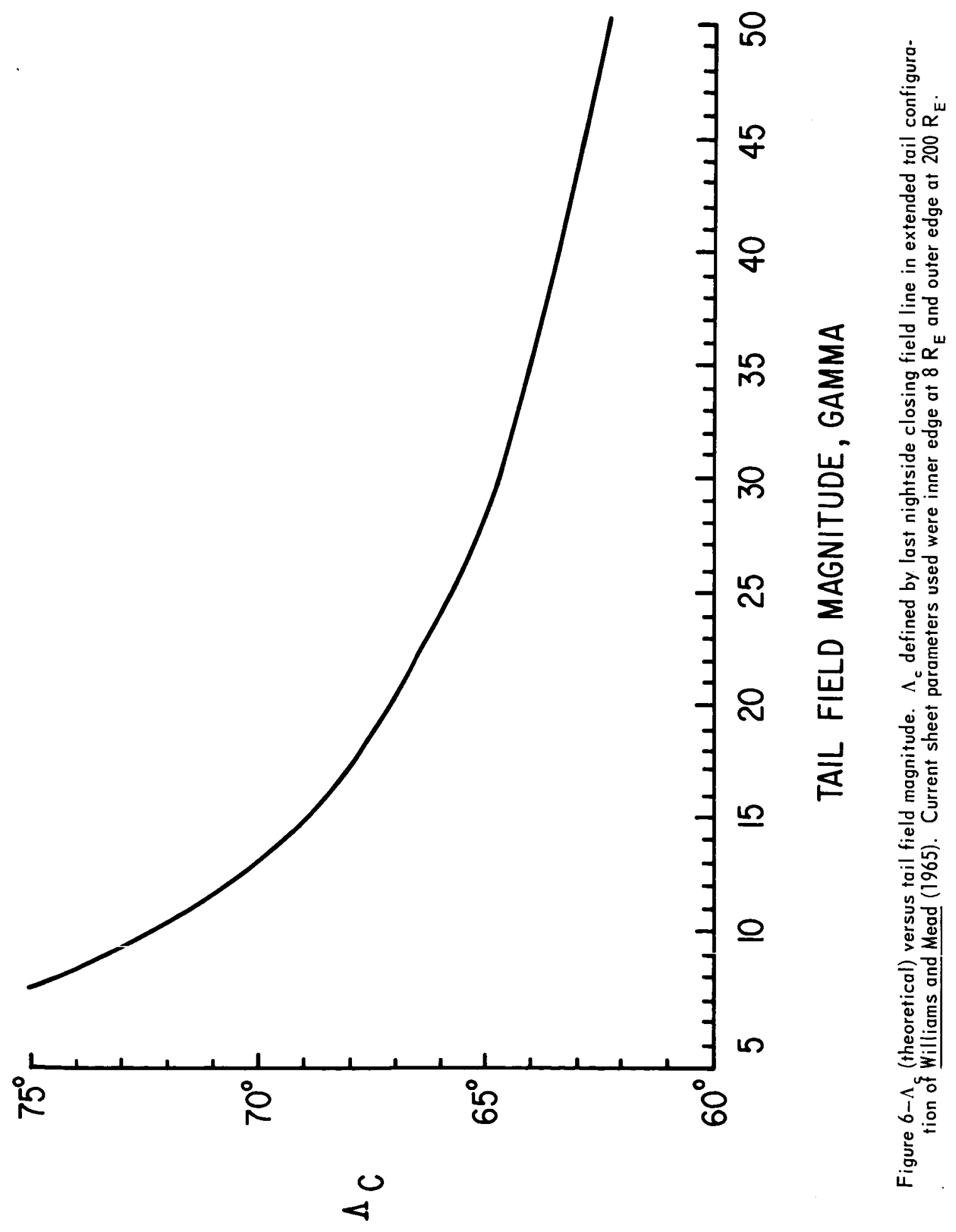



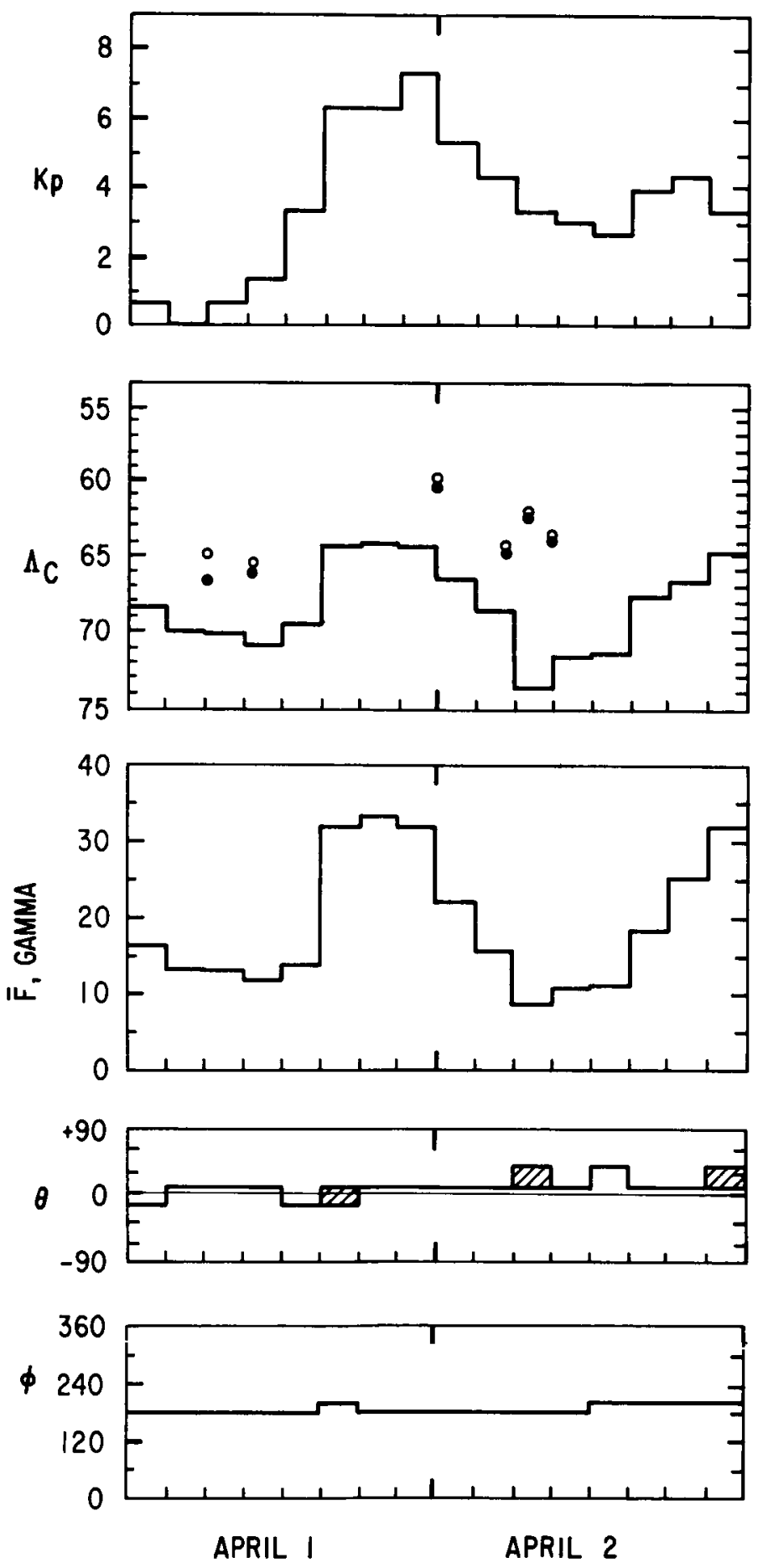

Figure 7-Correlation of $K_{p}, \Lambda_{f}$ (high latitude trapping boundary), and $\bar{F}$ (tail field strength) for the magnetic disturbance of April 1, 1964. Also shown are the solar ecliptic angles $\theta$ and $\phi$ defining the tail field direction. See text for discussion. 

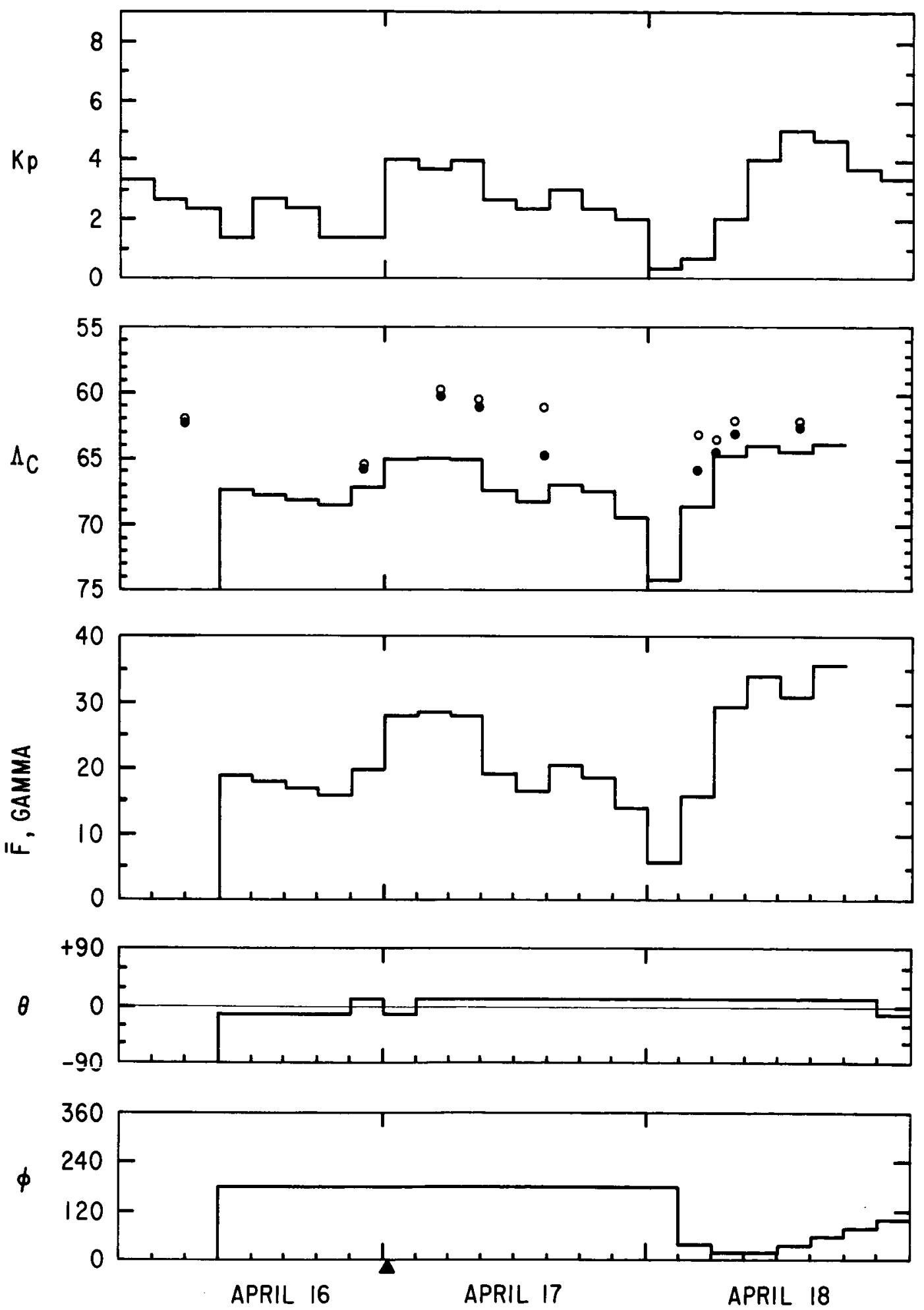

Figure 8-Correlation of $K_{p}, \Lambda_{c}$, and $\bar{F}$ for the April 27, 1964 event. $\theta$ and $\phi$ also shown. 

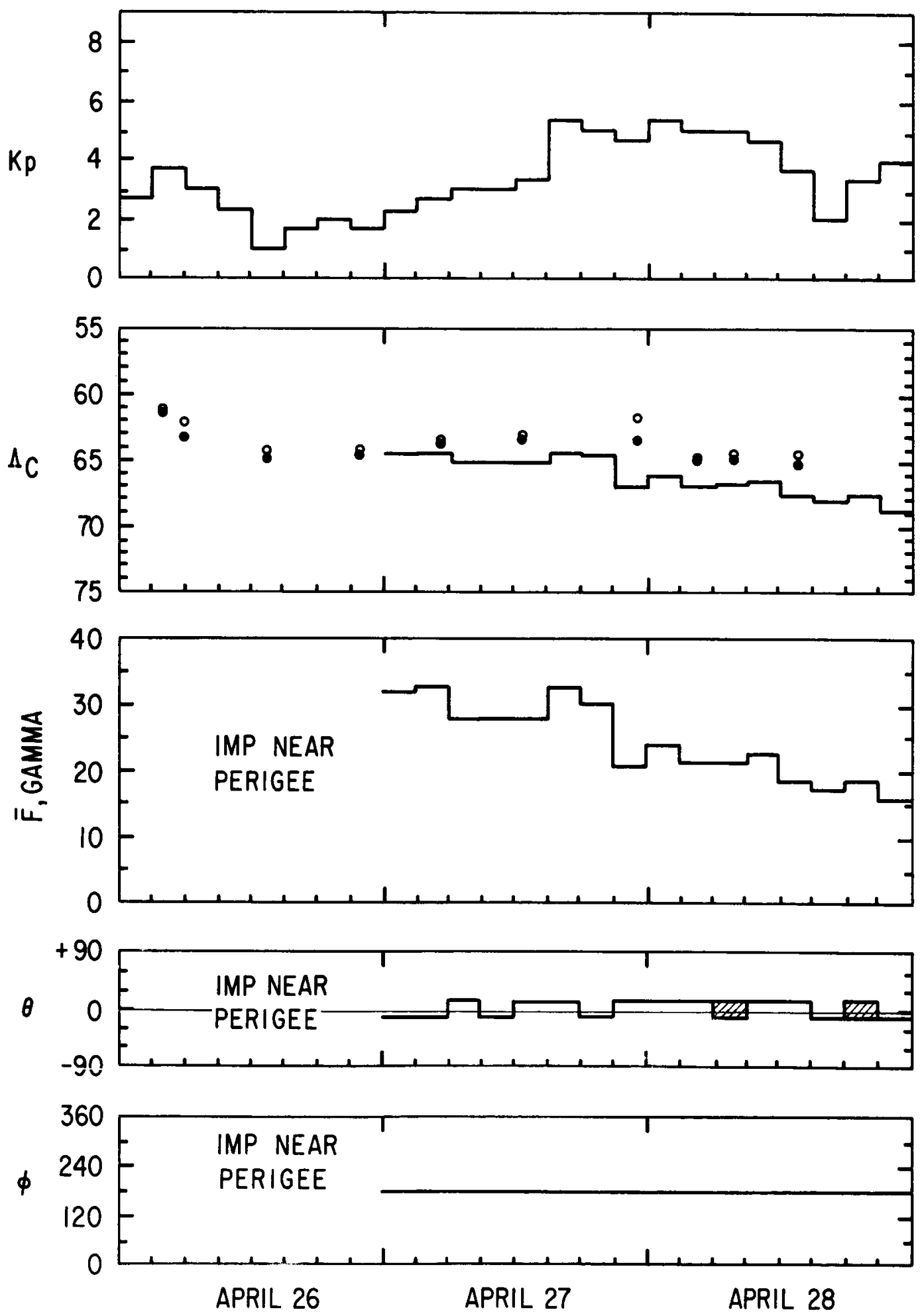

Figure 9-Correlation of $K_{p^{\prime}} \Lambda_{c^{\prime}}$ and $F$ for the April 27, 1964 event. $\theta$ and $\phi$ also shown. 

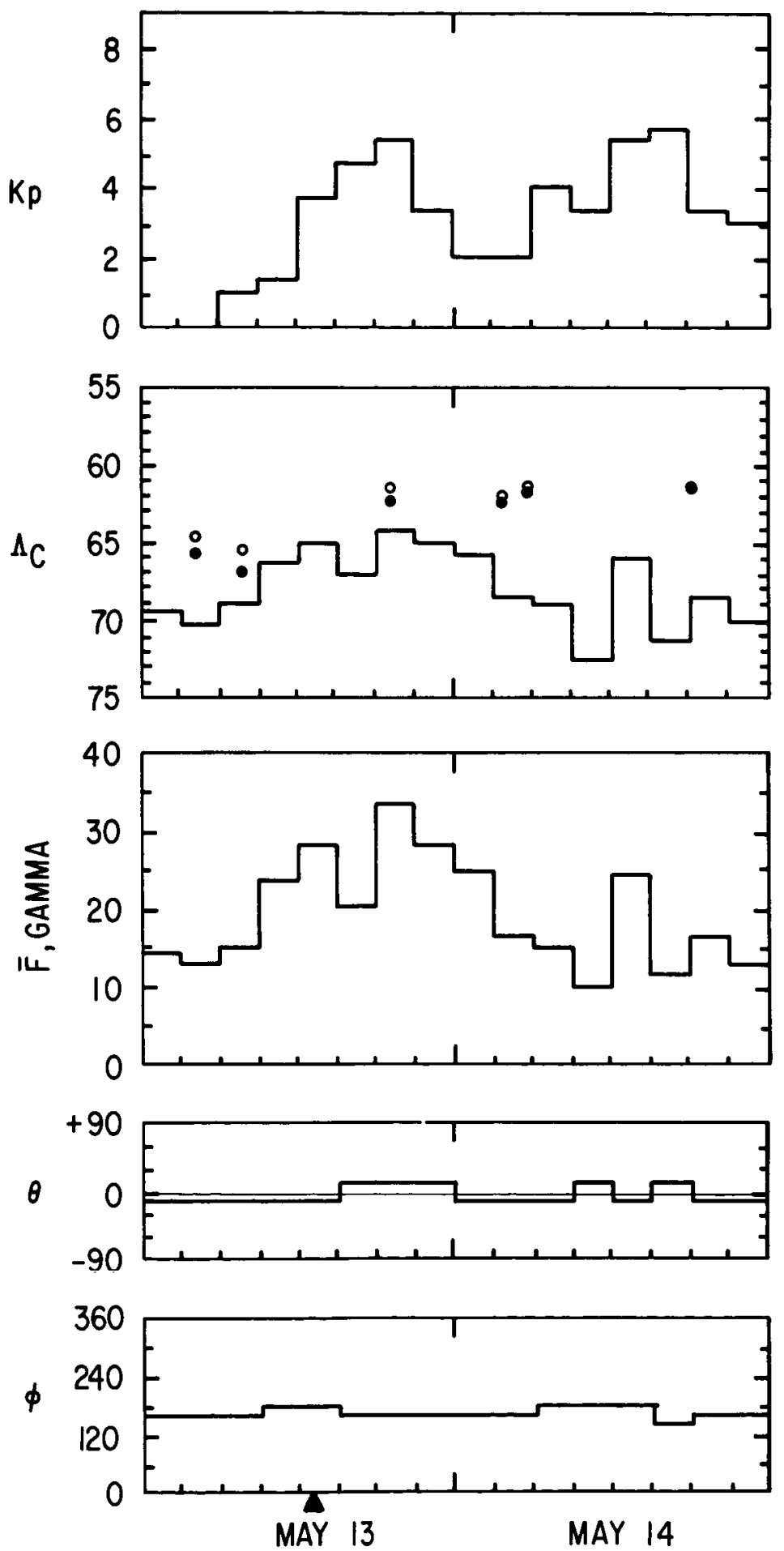

Figure 10-Correlation of $K_{p}, \Lambda_{c}$ and $\bar{F}$ for the May 13, 1964 event. $\theta$ and $\phi$ also shown. 

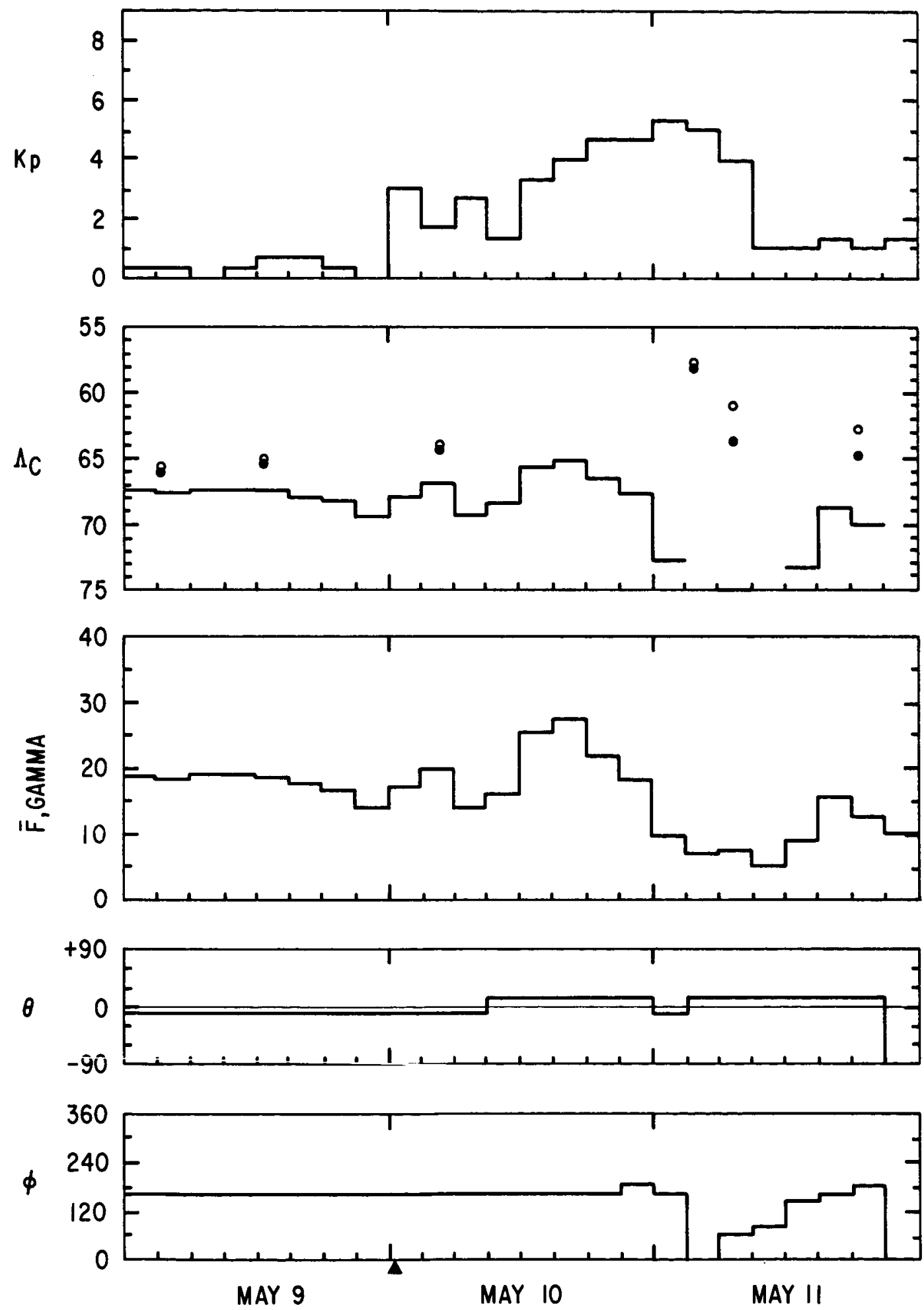

Figure 11-Correlation of $K_{p}, \Lambda_{c}$ and $\bar{F}$ for the May 10, 1964 event. $\theta$ and $\phi$ also shown. 

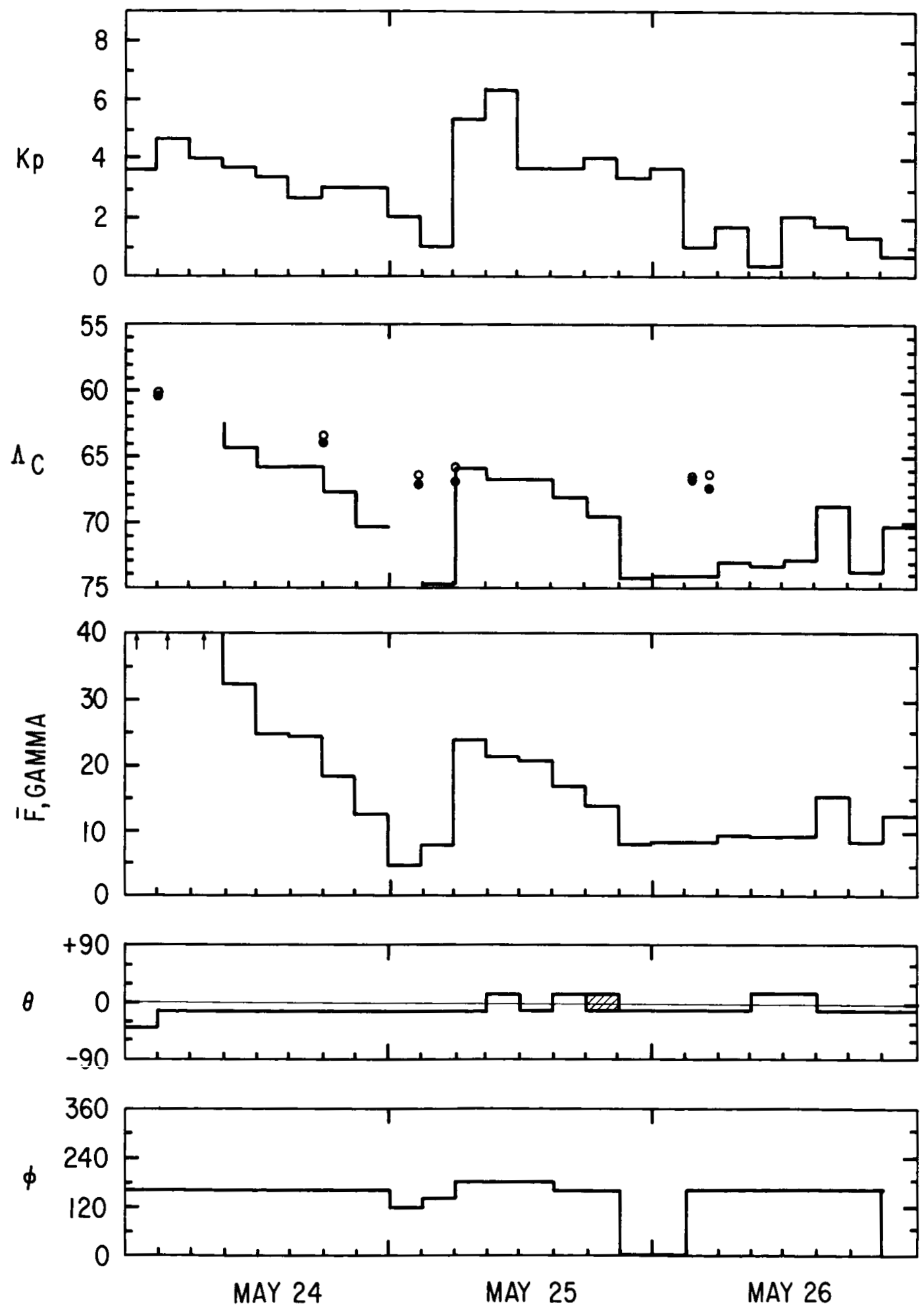

Figure 12-Correlation of $K_{p}, \Lambda_{e}$ and $\bar{F}$ during activity following the May 23, 1964 event. 